\title{
Shifts of Cohesion and Coherence in the Translation of Political Speeches
}

\author{
Aladdin Al-Kharabsheh (Corresponding author) \\ Dept. of English, The Hashemite University, PO box 330186, Zarqa 13133, Jordan \\ E-mail: alakh22@yahoo.com \\ Nadeen Hamadeh \\ Dept. of English, The Hashemite University, Jordan \\ E-mail: nadine.hammadeh@yahoo.com
}

Doi:10.7575/aiac.alls.v.8n.3p.100

URL: http://dx.doi.org/10.7575/aiac.alls.v.8n.3p.100
Received: 26/04/2017

Accepted: 15/06/2017

\begin{abstract}
Discourse Markers (DMs) are central to maintaining cohesive and coherent translations. Drawing on Halliday and Hassan's (1976) model to investigate the translation of DMs in political speeches, the study has verified the premise that tampering with the SLT's cohesion grid can adversely affect its relevant undergirding coherence grid. The study has revealed that any incurred cohesion shift in the act of translating would necessarily inscribe a parallel coherence shift, which fuse together to procure a noticeable translation loss. Analysis has isolated three major problems pertinent to translating English DMs into Arabic: (a) mistranslating explicit SL DMs, (b) no translation is given for implicit SL DMs, and (c) no translation is given for explicit SL DMs.
\end{abstract}

Keywords: discourse markers, cohesion shift, coherence shift, political speeches, explicit discourse markers, implicit discourse markers

\section{Introduction}

A possible problem, among a set of major ones, that translators may encounter is the one pertinent to discourse markers (henceforth, DMs), which are central to maintaining both cohesion and coherence, when translating from English into Arabic and vice versa. Cohesive and coherent translations play a pivotal role in the sense that readers of any given translated version will appreciate the textuality of what they read, i.e., DMs constitute a fundamental part of textual cohesion and coherence. In this study, the main focus will be on DMs in political discourse, as cohesion and coherence pose translation challenges to translators of political speeches in particular. Failing to render the cohesion-building devices properly in the target language (henceforth, TL) is likely to result in intolerable coherence shifts, i.e., the reader is likely not to gain control over the logic of the text, as propositions are likely to appear disconnected from one another (cf. Ventola, 1997 and Varela Pérez, 1999).

At another level, many sharp linguistic differences can be found between English and Arabic at all language levels: syntax, semantics, phonetics, etc. In this respect, Yehia (2015, p. 4) confirms that "there is a large potential for errors of interference when Arab learners produce written or spoken English due to the differences between the two languages at the different linguistic levels." For example, in the English linguistic system, there are implicit and explicit DMs, which can forge textual cohesion and coherence, whereas this is not the case when it comes to the Arabic linguistic system, which does not commonly feature implicit DMs. Therefore, translating English implicit DMs into Arabic may require exerting more effort, as such linkers may escape the recognition of translators.

The pragmatic aspect of DMs gains a special importance in translation. From a pragmatic perspective, Ismail points out that DMs "have a pragmatic effect, they add, sequence, contrast or conclude a number of ideas and they are essential to the overall persuasive effect of a text" (2012, p. 16). On his part, Sun (2013, p. 2) confirms that DMs should not be "seen as simply tying together adjoining clauses," as "[they] may indicate relations between stretches of text." So, DMs can help in shortening the distance between the speaker and the receivers in the sense that they facilitate the receivers' task of understanding the speaker. In other words, DMs may make the segmentation of utterances and ideas of any text more explicit, and so, the readers may identify the relations that readily exist between texts' segments. This argument can be supported by a recent study that has been carried out by Yehia (2015) who affirms that DMs "are characteristics of connected discourse, that is to say they contribute to discourse coherence, which signal the communicative intentions of discourse." Hence, translators should choose a TL DM that can serve the same 
pragmatic function as the source language (henceforth, SL) DM does, based on the SLT context, i.e., to produce a TL DM that can achieve an identical level of cohesion and coherence as that achieved by the SLT. Therefore, translators have to be aware of the pragmatic meanings that are beyond DMs "not because of the semantic aspects of the words themselves, but because the reader/hearer shares certain contextual knowledge with the writer/speaker of the text" (Tafish and Tahaineh 2011, p. 10).

From a translational point of view, cohesive and coherent relations achieved by SL DMs should be rendered carefully to the TLT by using proper TL equivalents. However, adopting an improper translation strategy in dealing with DMs may lead to a considerable semantic loss in the TL, which needs to be compensated for. Therefore, translators should analyze the SLT carefully in order to locate the exact meaning of the SL DM in question, and to identify the cohesive or coherent function(s) that it conveys within its linguistic SL context. In this respect, Tafish and Tahaineh advocate that translators should give a high priority to the semantics of DMs as to master the appropriate functions of them (2011, p. 11). This means that in the process of translating DMs, translators need to give utmost care to the semantic aspect of every DM in the two languages: the SL and TL. Thus, translators should seek to provide a functional and/or communicative TL DM that logically holds the meaning as approximately as possible to the meaning of the SL one in order to establish the right semantic link in the TLT. By so doing, the TL readership would receive an identical semantic level, and subsequently, an identical degree of cohesion and coherence to that achieved by the SLT.

Thus, it is axiomatic to say that failing to maintain cohesion and coherence may well result in a disconnected discourse. In this study, there will be an attempt to investigate the difficulties and problems associated with translating DMs and their functions and roles in maintaining cohesion and coherence in a selected corpus of King Abdullah II's political speeches. The underlying premise is that DMs can be viewed as significant cohesion and coherence-building devices that should be translated properly; otherwise, a considerable translation loss is likely to occur. In a nutshell, the study will attempt to verify the premise that tampering with any given SLT's cohesion can badly affect its relevant coherence. A large number of the DMs relevant to King Abdullah II's political speeches appear to be mishandled and mistranslated. As a result, they look to be replaced by analogous but ultimately different ones in the receiving language that inscribe shifts in coherence. This can be ascribed to the sharp linguistic and cultural differences between English and Arabic, and to the shallow scrutinizing of the co-texts and contexts in which DMs figure. Thus, savvy translators should take these dimensions into their serious account in order to be able to make informed decisions, and to be able to set forth the proper translation strategy, i.e., the strategy that can fulfill the cohesion and coherence functions and relations intended by the SL DM.

\section{Theoretical Background}

\subsection{Discourse Markers (DMs)}

Walord (2006, p. 4) defines DMs as "cues or road signs which guide our process of text comprehension and interpretation." He explains that these markers help us arrive at the suitable and acceptable interpretation. $\mathrm{He}$ also points out that DMs help make communication meaningful, interesting and effective. Blakemore (2002, p. 152) highlights the idea that "discourse markers encode structural relationships between segments of text or discourse". Blakemore (ibid., p. 152) argues that "discourse markers or connectives are defined in terms of the role they play in marking these structural relations between segments, and the key to their analysis lies in the classification of the kinds of relations that exist between text segments" (see also Stubbs, 1983, pp. 77-8; Schiffrin, 1987, p. 188; Rouchata, 1996, and Rey, 1997).

Blakemore (ibid, p. 1) emphasizes that "markers' meanings can be tackled according to what they 'indicate or mark,' but not according to what they 'describe'," and that these "expressions seem to encode information about the context in which the utterances that contain them are appropriate rather than information about their proposition content" (ibid., p. 9). She (ibid., p. 12) neatly states that "discourse connectives [...] must have pragmatic meaning because they do not contribute to the truth conditional content of the utterances that they contain," and that "some of the thoughts communicated by an utterance are communicated explicitly, while others are communicated implicitly" (ibid., p. 29). It also follows that "explicitly communicated information is regarded as being within the domain of semantics, while implicitly communicated information is said to fall within the domain of pragmatics" (ibid., p. 71).

Indeed, DMs represent a treacherous area for translators, as each language tends to deploy its own preferred patterns of connectedness between sentences. Baker (1992, p. 192) emphasizes that "languages vary tremendously in the type of conjunctions they prefer to use as well as the frequency with which they use such items." In her view, conjunction is "a device for signalling relations between chunks of information, [yet] it is naturally bound up with both the chunking of information, how much to say in one go, and with how the relations between such chunks of information are perceived and signalled" (Baker 1992, p. 192). Indeed, one marked difference in the use of conjunctions, which obtained a scholarly consensus, is that between English and Arabic.

Baker explains that English, in comparison to Arabic, "generally prefers to present information in relatively small chunks and to signal the relationship between these chunks in an unambiguous ways, using a wide 
variety of conjunctions to mark semantic relations between clauses, sentences, and paragraphs" (ibid., pp. 192-3). Besides the types of conjunction offered by Halliday and Hasan (1976), English also depends on "a high-developed punctuation system to signal breaks and relations between chunks of information" (ibid., p. 193). Arabic, on the other hand, "prefers to group information into very large grammatical chunks. It is not unusual for Arabic paragraphs to consist of one sentence" (ibid., p. 193). In addition, Arabic prefers to employ "a relatively small number of conjunctions, each of which has a wide range of meanings which depend for their interpretation on the context, thus relying heavily on the reader's ability to infer relationships which are only vaguely alluded to by the writer" (ibid., p. 193).

Baker argues that "short sentences, a varied array of conjunctions, and absence of the typical conjunctions (mainly wa, fa, and a few other particles) are associated with translated Arabic texts - original Arabic texts do not normally display these features" (ibid., p. 193). This view is echoed by Dickins (2002, p. 131), who neatly puts that "in many genres at least, Arabic sentences are typically longer than English sentences, and sentences and clauses in Arabic are typically connected either by one of the three basic connectives 'wa', 'fa' and 'thumma', or by the use of one of the simple secondary connectives such as 'Haythu', 'idh', etc. ".

\subsection{Cohesion and Coherence}

Cohesion and coherence are text-centred notions, designating operations directed at textual substance. Though the two notions pertain to connectivity, and has often been confused or conflated with each other, they are always dealt with as two distinct realizations in text-linguistics (e.g. Carrell, 1982; Van Dijk, 1995) and translation studies (e.g. Papegaaij and Schubert, 1988; Vehmas-Lehto, 1991; Hu, 1999).

According to Bell, cohesion and coherence are "distinct from each other but share one crucial characteristic; they both have the function of binding the text together by creating sequences of meanings" (1991, p. 164). Halliday and Hasan (1976, p. 23) elaborate that cohesion means the coherence of a text with itself, whereas coherence is the coherence of the text with reference to its context of situation. Thus, for any given text to be coherent, "it must deploy the resources of cohesion in ways that are motivated by the register of which it is an instance" (Halliday 1994, p. 339). On the other hand, cohesion refers to the elements in texts that make it cohere, e.g., cohesive elements that make one part of a text 'belong' together with another. For BlumKulka (2000, pp. 298-299), coherence can be seen "as a covert potential meaning relationship among parts of a text, made overt by the reader or listener through processes of interpretation", and "as the realization(s) of the text's meaning potential (italics omitted, ibid., p. 304). Cohesion, on the other hand, can be viewed as "an overt relationship holding between parts of the text, expressed by language specific markers" (italics omitted, ibid., p. 299).

In the lenses of de Beaugrande and Dressler (1981, p. 113), cohesion and coherence "are the most obvious standards of textuality". For them, cohesion "subsumes the procedure whereby surface elements appear as progressive occurrences such that their sequential connectivity is maintained and made recoverable", whereas, coherence "deals with the procedures by which elements of knowledge are activated such that their conceptual connectivity is maintained and made recoverable" (ibid., p. 19). It is obvious that cohesion is explicit, as it is engendered by surface connectivity (i.e. surface elements), whereas coherence is implicit, as it is engendered by conceptual connectivity (cf. also Sanders, 1987, p. 7; Halliday and Hasan, 1995). Similarly, Hatim and Mason (1990, p. 195) view coherence cognitively, as "the procedures which ensure conceptual connectivity, including (1) logical relations, (2) organization of events, objects and situations, and (3) continuity in human experience". They also stress that the sequence of coherence relations, such as cause-effect, problem-solution, etc., should remain constant in translation from the ST to the TT, but the ways in which this underlying coherence is reflected on the surface of text, the cohesion, are more likely to be language-specific or text specific. They also add that both, i.e., cohesion and coherence need to be maintained if communication is to be successful (ibid., p. 195).

These two concepts are indissolubly interrelated and interdependent, as a careful selection of cohesive devices will assist in building coherence, which is maintained "by continual interaction of TEXTPRESENTED KNOWLEDGE with PRIOR KNOWLEDGE OF THE WORLD” (de Beaugrande 1980, p. 19). Based on this, Dressler (1998) stresses on coherence as the way in which a text connects together semantically, pragmatically and thematically, and argues that the constitution of coherence is not textimmanent, but performed by inferencing. This inferencing capitalizes on the readers' domain knowledge or experience and their ability to draw informed inferences (cf. Weissberg, 1984). In the same vein, Neubert and Shreve (1992, p. 94) describe a coherent text as having "an underlying logical structure that acts to guide the reader through the text", while Chilton (2004, p. 65) emphasizes that "the linguistic form of the utterances are 'coherent' only if certain presumptions are attributed to the speaker, presumptions which the speaker assumes are (or perhaps ought to be) accepted by the hearer."

Indeed, this dichotomy is of a direct relevance to the translation context, as it has been dealt with differently by different scholars (e.g. Hatim and Mason, 1990; Baker, 1992; Hatim and Munday, 2004; Kostopoulou, 2007). Defending the premise that the process of translation necessarily involves shifts both in textual and discoursal relationships, Blum-Kulka (2000, pp. 299-312) makes a distinction between shifts on the level of cohesion and shifts on the level of coherence. The former is perceived as shifts in types of cohesive markers employed in translation that are likely to impinge upon translation in two ways: (a) shifts in levels of 
explicitness, i.e. when the general level of the TLT's textual explicitness is higher or lower than that of the SLT, (b) shifts in text meaning(s); i.e. when the explicit and implicit meaning potential of the SLT changes through translations. Concurring with Edmondson (1981, quoted in Blum-Kulka, 2000, p. 304) who equates coherence with the text's interpretability, Blum-Kulka differentiates between reader-focused and textfocused shifts of coherence. Reader-focused shifts have to do with a change in reader audiences through translation, whereas text-focused shifts pertain to the process of translation itself, i.e., shifts that are engendered by "particular choices made by a specific translator, choices that indicate a lack of awareness on the translator's part of the SL text's meaning potential" (Blum-Kulka, 2000, p. 309; see also Blum-Kulka, 1986, p. 19).

In an equivalence-oriented investigation, it may be rightly posited that coherence, i.e., the implicit connectedness of thought undergirding the surface text, would remain constant in translation (Hatim and Mason, 1990, p. 195). However, the ways in which this coherence is reflected on the textual surface, i.e., the kind of cohesive devices used, may not be the same as the SL's, for reasons pertinent to peculiarities and/or idiosyncrasies of languages, text types and genres, registral differences, and socio-cultural differences. In the current study, coherence should be understood as the intended sense, rather than the intended meaning (Hatim and Mason, 1990, p. 194), since in view of de Beaugrande and Dressler (1981, p. 84), meaning labels "the potential of a language expression" for representing and relaying knowledge ("virtual meaning"), whereas sense labels "the knowledge that actually is conveyed by expressions occurring in a text". They additionally say that "many expressions have several virtual meanings, but under normal conditions, only one sense in a text" (ibid., p. 84).

This aspect has its own bearing on translation, owing to the fact that translators do not deal with isolated structures, but with structures in texts-in-contexts, which entail searching for the intended sense of a specific structure in a specific text-in-context. This is of a high importance in cases where the explicit markers may decline to establish the intended sense. Thus, the translator's mammal task is to find this intended sense, then, to preserve it in translation, through the proper pragmatic use of cohesive devices which, as it will be shown in this study, may be incongruous between linguistically and culturally remote languages, such as English and Arabic. The careful pragmatic selection of TL cohesive devices, presumably equivalent to their ST counterparts, can warrant rendering the intended sense of the ST in the TL. As a corollary, the TT coherence can be built through interaction between textual knowledge/information and the TL readership's encyclopedic knowledge, experiential knowledge, and even sometimes, specialist knowledge.

\subsection{Halliday and Hasan's (1976) Model}

According to Halliday and Hasan (1976, p. 4), cohesion occurs "where the interpretation of some element in the text is dependent on that of another". Yet, "when this happens, a relation of cohesion is set up, and the two elements, the presupposing and the presupposed, are thereby at least potentially integrated into a text" (ibid., p. 4). They identify four types of cohesion, which include reference, substitution/ellipsis, lexical cohesion, and conjunction. What is of utmost concern in this study is conjunction. Indeed, conjunction differs from the other three types of cohesion because attention is paid to the meaning of the cohesive relation itself, rather than on the elements that hang together (ibid., pp. 226-227). Indeed, there is a wide spectrum of cohesive relations under the broad rubric of conjunction, and the authors stratified them according to their function: additive ('and', 'or else', 'furthermore', 'for instance', 'similarly', 'on the other hand'), adversative ('but', 'nevertheless', 'in fact', 'on the other hand', 'instead', 'rather', 'in any case'), causal ('therefore', 'with this in mind', 'it follows', 'in that case', 'otherwise'), and temporal ('next', 'at once', 'meanwhile', 'finally', 'up to now', 'in short'). The study will heavily rely on these conjunctions in its analysis of the selected examples.

Conjunction is yet another cohesive device discussed by Halliday and Hasan (1976), and is quite different in nature from reference, substitution, or ellipsis. According to Halliday and Hasan (1976, p. 226), the cohesive function of conjunctions is indirect and is realized "by virtue of their specific meanings," which "presupposes the presence of other components in the discourse". Conjunctions relate "linguistic elements that occur together in succession," thus creating ties between segments of text (Halliday and Hasan, 1976, p. 227). They combine "any two textual elements into a potentially coherent complex semantic unit" (Thompson, 1996, p. 156). While reference, substitution, and ellipsis are "clearly grammatical" because they involve closed systems (e.g., such systems as those of person, number, proximity, degree of comparison, or presence/absence), conjunction is "on the border-line of the grammatical and lexical" (ibid., p. 303). As Halliday and Hasan point out, "the set of conjunctive elements can probably be interpreted grammatically in terms of systems, but ... some conjunctive expressions involve lexical selection as well, e.g., "moment" in "from that moment on" (ibid., pp. 303-304).

In Halliday and Hasan's (1976) Cohesion in English, four types of conjunction are identified: additive, adversative, causal, and temporal (p. 238). Additive conjunction is "a generalized semantic relationship in the text-forming component of the semantic system" (p. 234), more commonly known as coordinating conjunction, such as that realized with "and" or "besides." Adversative conjunction is a relation used as "contrary to expectation" (p. 250). Some examples of adversative conjunctions include "but," "yet," 
"however," "(al)though," "nevertheless," etc. Causal conjunction is a cause-effect relation (of reason, result, or purpose) and is expressed by such examples as "so," "thus," "hence," "therefore," etc. (p. 256). Lastly, temporal conjunction is a relation of sequence in time, when one element in a text "is subsequent to the other" (p. 261). Examples of temporal conjunctions include "then," "thereupon," "later," etc.

\section{Methodology}

Examples will be taken from some speeches delivered by King Abdullah II that have been selected from the website of the Royal Court. This is an official site of His Majesty King Abdullah II of Jordan, and it is owned and operated by the Royal Hashemite Court, and where all political speeches in both versions (English and Arabic) can be accessed. A corpus consisting of fourteen topic-based political speeches, which were delivered by His Majesty King Abdullah II of Jordan during the period of 2011-2015 have been selected as to be examined with special attention to be given to the translation of DMs. Data will be analyzed and classified by drawing on Halliday and Hassan's (1976) model of DMs where different types of cohesion have been described including: reference, substitution, ellipsis, and conjunction. The study will only focus on conjunction.

Analysis of the selected examples will be carried out through Semantic Characterization and Pragmatictranslatorial Characterization. Semantic Characterization involves the identification of the exact meaning of the cohesive DMs within its immediate linguistic SL context. Pragmatic-translatorial Characterization, on the other hand, is concerned with comparing and contrasting the SL DM and its TL counterpart both pragmatically and translationally in terms of cohesion and coherence, i.e., as to see whether or not the cohesive DMs used by the royal court translators in the produced TLTs trigger cohesion and coherence shifts, or maintain, more or less, the same cohesion and coherence relations and functions, as in the SLTs. Finally, the discussion of each example will be sealed off by giving a workable translation that can do the needed job semantically, pragmatically and translationally. In the following pages, we set out from this translatorly standpoint, yet move beyond it to consider DMs not merely as semantic linkers, but as pragmatic connectives that play havoc with coherence and leave not unaltered the TLTs.

\section{Discussion}

Let us start off by reminding that the mechanism that will be adhered to in this discussion runs as follows: first, the English SL example will be given; then, it will be followed by its Arabic translation. Under each example, the title of the speech from which the example has been taken will be mentioned between curly brackets. After this, an analysis that hinges on comparing and contrasting the two versions will be made, and towards the end of every discussed example, a suggested translation will be provided. Analysis of data reveals that three major problems can be spotted when it comes to translating English DMs into Arabic: (1) mistranslating explicit SL DMs, (2) no translation is given for implicit SL DMs, and (3) no translation is given for explicit SL DMs. Now let us take up each of these problems for a discussion that will be supported by authentic examples.

\subsection{Mistranslating Explicit SL DMs}

Under this problem, four contextualized examples, taken from different speeches, will be given:

(1a) SL Text:

"Syria's future will depend on the Syrian people. But the world has the duty, the interest, and the power to help."

\section{(1b) TL Text:}

$$
\text { " لكن مستقبل سوريا سيعتمد على الثعب السوري لا غيره، وِعلى المجتمع الدولي ومن مصلحته، تقديم المساعدة، وهو قادر على ذلك." }
$$

\{From the Plenary Session of the 68th General Assembly of the United Nations\}

In example (1) above, the translation, which was given by the Royal Court translators, clearly shows that the adversative DM but in the second sentence (1a) is mistranslated in the TL without any plausible justification. As it is well-known, the function of but is to express contrast, i.e., it indicates that the following utterance contrasts with the preceding one, but unfortunately this function was not communicated over in the TLT, as the Arabic additive $w a$ (i.e., , lit. and) was used instead. Linguistically, the DM $w a$ in (1b) serves a completely different function in Arabic that is addition, thereby changing the sequence of the implicit connectedness between the two sentences, i.e., changing the sequence of coherence between two chunks of information from contrast to addition. Another serious problem has to do with the insertion of the Arabic adversative but i.e. laakin كن in the TLT in an initial position of the first sentence, unlike the case in the SLT, as it was in an initial position of the second sentence. This cohesion shift reverses the explicit semantic relationship between the two chunks in general, and, once again, flips the contrast-relationship that exists between the two clauses upside down, i.e., it flips the relevant coherence upside down. Indeed, the provided TLT

$$
\text { " لكن مستقبل سوريا سيعتمد على الثعب السوري لا غيره، وعلى المجتمع الدولي ومن مصلحته، تقديم المساعدة، وهو قادر على ذلك." }
$$

corresponds, in terms of cohesion and coherence, exactly to the following sentence (i.e. a back translation):

"But Syria's future will depend on the Syrian people and the world has the duty, the interest, and the power to help." 
whereas the original SLT is as follows:

"Syria's future will depend on the Syrian people. But the world has the duty, the interest, and the power to help."

By comparing and contrasting the two sentences above, astute readers can easily trace the serious cohesion shifts the translator made to the SLT in the TLT, which consequently led to a shift in the relevant coherence. To maintain a level of cohesion and coherence similar to that in the TL, some procedures need to be taken: first the Arabic adversative but i.e. laakin كن , inserted in the initial position of the first sentence, should be weeded out, secondly, it should be shifted around to an initial position of the second sentence of the TLT, exactly as is the case in the SLT, and thirdly, it is necessary to start the first sentence in the TLT with the verb سيعند as this is the preferred Arabic sentence pattern, i.e., the SLT should have been translated pragmatically into:

$$
\text { " سبعتمد مستقبل سوريا على الثعب السوري لا غيره ، لكن من واجب المجتمع الدولي ومن مصلحته، تقديم المساعدة، وهو قادر على ذلك". }
$$

(2a) SL Text:

"As the Arab Spring demanded dignity for all, $\underline{\text { so }}$ it demanded the end of exceptionalism."

(2b) TL Text:

$$
\text { " فِلر بيع العربي ينادي بالكر امة للجميع، وِوضع حد لسياسة الاستثناء." }
$$

\{From Pre-67th Plenary Session of the United Nations General Assembly\}

Casting a quick glance at example (2) above, it is noticeable that there are two cohesion-building DMs that were mistranslated in the TLT. These are the adverbial DM as and the causal DM so. The surface connectivity made by these two DMs in the SL gives the sense that the Arab Spring demanded dignity for all: a general demand that subsumes a number of other demands, and that "the end of exceptionalism" is just one of them. Thus, the use of the DM $a s$ in the first clause, with the DM so in the second indicates that "the end of exceptionalism" is a demand that falls under "dignity for all", or that branches out from the general demand (along with other demands) that resulted from the Arab Spring. In other words, the interaction of these two DMs gave rise to the following conceptual sequential meaning, i.e. to the following coherence: the general demand having sub-demands.

Indeed, the provided translation does not seem to have retained the cohesion and coherence linkages, as the SLT's DMs were not adequately translated, which triggered marked cohesion shifts that seem to have led to

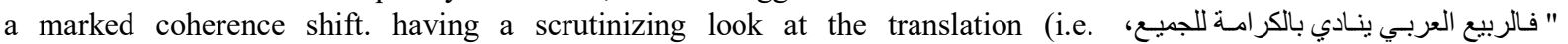
a ووضـع حـد لسياسـة الاسـنثناء." it can be noticed that amalgamation of the Arabic DM fa (i.e. so/therefore/since/insofar), and the Arabic additive $w a$ (i.e., , lit. and), communicate the idea that the Arab Spring called for two main demands in parallel (but not as one being subsumed in the other): dignity for all and the end of exceptionalism. These cohesion and coherence shifts can be explained by the fact that the translators did not seem to have grasped the exact meaning of the English DM as, as it was mistakenly understood as the DM so. This was self-evident in their choice of the Arabic DM $f a$ (i.e. $\dot{\omega}$ ), which is normally agglutinated to the initial of the first word in a sentence or clause to draw a conclusion. Having understood the first DM (i.e. as) as so, the translators were then confronted with another so, i.e. the second DM at the beginning of the second clause, which propelled them to convert it into the additive $g$ (i.e. and), as to get rid of redundancy.

A careful examination of the context can reveal that the first DM as signals the meaning of since, and so it should be rendered into Arabic as wa-bima anna (i.e. وبمـا أن) or wa-latalama (i.e. ولطالدا أن) since these are the most common Arabic DMs that can translationally correspond to such an English DM as. The second DM so, on the other hand, signals conclusion-drawing, and so it should be rendered into the TL as $f a$ ف or wa-litha ولذا gast as these the most valid options to meet the SL DM. Based on all has been mentioned, the following translation can be suggested:

$$
\text { "وبما أن الربيع العربي ينادي بالكر امة للجميع، فهو ينادي بوضع حد لسياسة الاستثناء". }
$$

(3a) SL Text:

"Today, almost three generations later, we have learned that it is not enough to make the right choices. We must also pursue effective action. Not only as nations, but as nations united,..."

(3b) TL Text:

$$
\text { "و اليوم وبعد ثلاثة أجيال تقريبا، تعلمنا أن مجرد اتخاذ الخيارات الصحيحة ليس بالأمر الكافي لوحده، بل يجب علينا أن نتبع ذلك بالعمل الجاد كِعوب }
$$

\{From Pre-67th Plenary Session of the United Nations General Assembly\}

Obviously, the correlative conjunction not only...but is used in the SLT (i.e. example 2 above) to create a precise parallel structure that can heighten clarity, reduce ambiguity, and lend elegance to one's style. So, the first part joined by the first word of the pair is a grammatical mirror image of the part joined by the second word of the pair. Used as a cohesion-building marker to provide the implicit proposition that we are not only nations, but nations united is a balance that was eschewed unnecessarily in the TLT, i.e. in 
متحدة. The Royal translators reduced this correlative DM into the simple Arabic DM kaaf 5 (i.e. S lit. as or like), thereby creating a simile structure (i.e. كثعوب متحدة, lit. like united nations). Hence, they likened nations to nations united, a coherence shift that gives a flawed conceptual connectivity, let alone its failure to maintain the precise parallelism and emphasis as that in the SLT. Indeed, Arabic is no short of grammatically counterpart structures in this regards, as there are two main correlative variants that can also be translationally equivalent to English not only...but (also) that. These include the following:

$$
\begin{aligned}
& \text { ليس... فحسب... وإنما (ايضا)... ل laysa...fahasb...wa-innama ('aydan ) } \\
& \text { laysa...faqat...bal ('aydan) ل }
\end{aligned}
$$

So, in the first part of a parallel structure, there can be laysa..fahasb ليس... i.e. not only, and in the second innama ('aydan) إنما (ايضـا) i.e. but (also), or alternatively, laysa faqat ليس فقط i.e. not only in the first, and bal ('aydan) بل (ايضـا) i.e. but (also) in the second. Thus, to keep both the explicit correlative DM (i.e. not only...but), and more or less, the same coherence in the TL, the following two translations, embracing the two already explained variants, can be suggested:

$$
\begin{aligned}
& \text { "و اليوم وبعد ثلاثة أجيال تقريبا، تعلمنا أن مجرد اتخاذ الخيار ات الصحيحة ليس بالأمر الكافي لوحده، بل يجب علينا أن نتبع ذلك بالعمل الجاد ليس مجرد }
\end{aligned}
$$

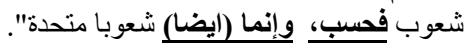

$$
\begin{aligned}
& \text { "و اليوم وبعد ثلاثة أجيال تقريبا، تعلمنا أن مجرد اتخاذ الخيار ات الصحيحة ليس بالأمر الكافي لوحده، بل يجب علينا أن نتبع ذلك بالعمل الجاد ليس مجرد } \\
& \text { شعوب فقط، بيل (ايضا) شعوبا متحدة". }
\end{aligned}
$$

(4a) SL Text:

"And we have an asset even more important: our people. They are young, aspiring, and globally-aware. They are active users of the internet, social media and new technology. They know regional demand for content, apps, and platforms indeed, they are helping to drive that demand."

(4b) TL Text:

"كما يوجد لدينا ثروة أكثر أهمية، وهي شعبنا الثـاب الطموح الملم بثقافة العـالم وأحو الـه. و الأردنيون مقبلون بنشاط على استخدام شبكة الانترنت ووستائل

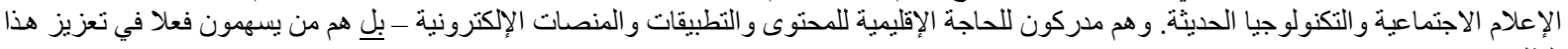

الطلب."

\{From the "Innovative Jordan" Conference - University of California at Berkeley\}

The boldtyped conjunctive adverb indeed in example (9) above is pragmatically used towards the end of a sentence as to draw a conclusion. This is substantiated by the punctuation mark, the dash, that precedes it. In English, the use of dash means that the part that comes after it is the most important one in the sentence. This support the argument that the DM indeed in this context has the pragmatic function of drawing a conclusion, i.e. "they are helping to drive that demand." In the TLT, the use of Arabic DM bal بل (lit. rather) was inappropriately employed as a translation equivalent for the DM indeed. Cohesion-wise, the Arabic DM bal بل does not serve the same function as SL one, i.e., indicating that what will follow it will be a main conclusion or a main consequence of what came before it; rather, it is generally used in Arabic to resume talking and usually what comes after it is more specific than what preceded it. This is what is not meant in this example.

Rendering the SL DM indeed into the Arabic DM bal بـ (9b) causes not only a cohesion shift but a concomitant coherence shift that affects the overall meaning of the sentence. Interestingly enough, the Arabic DM haqqan حقا w which is a literal translation of the English DM indeed also serves the same

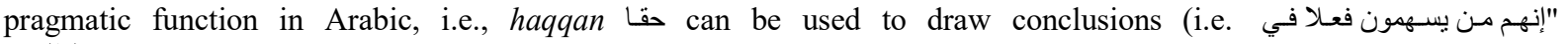
(تعزيز هذا الطلب , especially if it figures in the last sentence of a discussion, or in the last paragraph of a scholarly article. To regain the cohesion and coherence balance in the sentence, the following suggested translation can be a fairly satisfactory one:

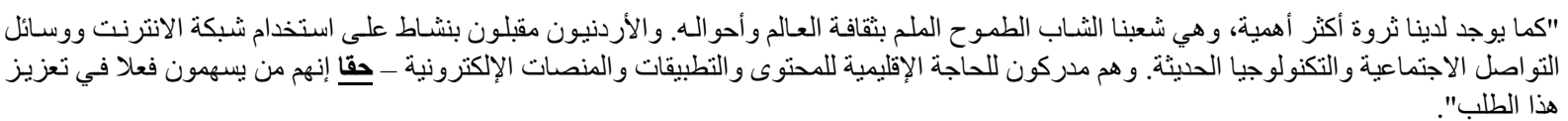

\subsection{No Translation is Given for the Implicit SL DMs}

Under this problem, four illustrative examples will be given. In this section, boldtyped curly brackets are used in both the SLT as well as TLT as to point to the place of the implicit DM.

\section{(5a) SL Text:}

"The historic transformation going on in my region today won't be achieved by formulas; it will come when all our citizens feel truly represented. Jordan seeks a House of the Future that includes all. $\{\quad\}$ We are building our future on the solid foundation of majority consensus, minority rights, a democratic culture of active citizenship, and peaceful, evolutionary change." 
(5b) TL Text:

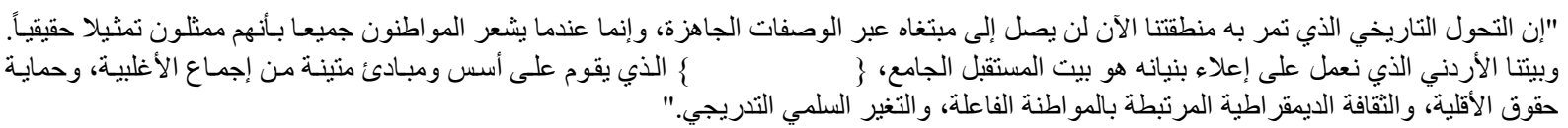

\{From the Plenary Session of the 68th General Assembly of the United Nations\}

The common fact that Arabic favours explicitation over implicitation in writing constitutes the point of departure of this section. It is typical in English to produce coherent texts without employing any cohesive markers at all, as example (5) above can reveal. The curly brackets in (5a) point to the place of the implicit DM in the SLT, i.e., the one recoverable at the beginning of the third sentence such as for this purpose; yet, this DM has to be made explicit in the TLT wa-lihatha al-gharad (i.e. ولهذا الغرض) as to maintain the underlying coherence of the text. Oblivious to such adverse consequences in Arabic, the translators appear to have unconsciously overlooked such a DM in their rendering of this text, as they linked up the third sentence with the preceding ones through the relative pronoun al-lathi الذي (i.e. which/that).

In the SLT, the conceptual connectivity goes as follows: "Jordan seeks a House of the Future that includes all", and for this purpose, our future should be built "on the solid foundation of majority consensus, minority rights, a democratic culture of active citizenship, and peaceful, evolutionary change." However, the coherence that the TLT communicates runs as follows: "Jordan seeks a House of the Future that includes all", which rests "on the solid foundation of majority consensus, minority rights, a democratic culture of active citizenship, and peaceful, evolutionary change." Obviously, the difference between the two kinds of coherences requires no further emphasis. Again, the translators should have made this causal relation explicit in the TLT. A possible translation that may yield a coherence in the TL identical to that in the SLT is the following:

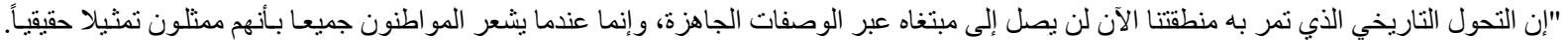

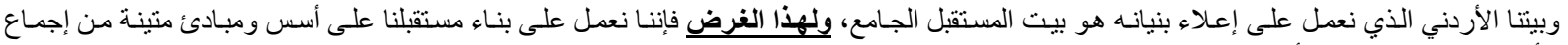

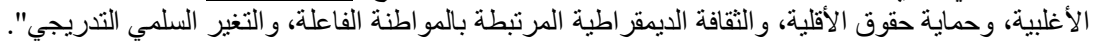

(6a) SL Text:

"Jordan has already begun. For us, political and economic reform go hand-in-hand. $\{\quad\}$ We recognize that the singlemost powerful generator of inclusive growth and jobs is a real partnership, drawing on the strengths of the private sector, public sector, and civil society."

(6b) TL Text:

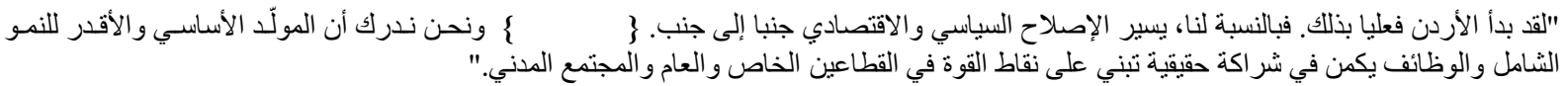

\{From the 9th World Islamic Economic Forum\}

Having a quick look at example (6) above shows that SLT harbours an implicit DM, traceable at the beginning of the second sentence, but which was kept implicit in the TLT too. Based on the SLT's context, a possible recoverable implicit causal DM that can fill the slot in the TLT is because (i.e. li'anna لأن or bisabab بسبب). Thus, a sound interpretation of the SLT can reveal its underlying coherence: "for us, political and economic reform go hand-in-hand, because we recognize that the single-most powerful generator of inclusive growth and jobs is a real partnership, drawing on the strengths of the private sector, public sector, and civil society." Adherence to the SL's grammatical system in the translated version can be accounted for by the fact that the Royal Court translators may have resorted to formal equivalence, i.e., giving prominence to preserving the formal properties of the SLT. The absence of the implicit DM because in the SLT does not imply that it has a flawed coherence, on the contrary, the text is quite coherent.

However, keeping this DM implicit in the TLT is problematic, as it gives a different coherence underneath the surface of the text. As a result of the lack of awareness on the part of the translators, the Arabic additive wa (i.e. $g$, lit. and) was provided, just to link up the two sentences together, not because they are aware of the existence of the implicit causal DM in that slot, and that the use of such an additive DM (i.e. wa) is just a miscalculated option. Clearly, using the additive DM wa in the TLT instead of li'annahu لأنس (i.e. because) enabled furnishing the following different coherence in the TLT: "for us, political and economic reform go hand-in-hand, and we recognize that the single-most powerful generator of inclusive growth and jobs is a real partnership, drawing on the strengths of the private sector, public sector, and civil society." The English causal DM because can be a proper DM in the SLT as to establish a cause-effect relationship between the sentence that precedes the curly brackets and the one that follows them, i.e., the sentence that precedes the DM is the effect, whereas the sentence that comes after the DM is the cause. By contrast, the Arabic additive $w a$ is used in the TLT as a simple cohesion-building device just to connect clauses together; yet, it does not serve the function of the causal DM because, i.e., it cannot replace it explicitly. Therefore, this implicit DM should have been translated into TL as follows: 


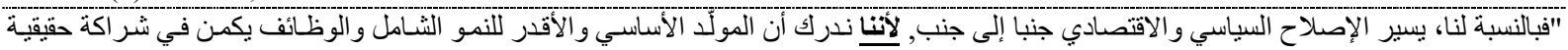

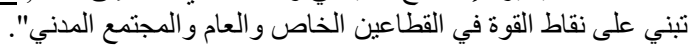

(7a) SL text:

"This Forum recognizes the creative drive, and the forward-looking enterprises, that make up the Islamic economic world today. $\{\quad\}$ Billions of consumers, of every faith and region, can benefit from the partnerships you make here. I wish you every success."

\section{(7b) TL text:}

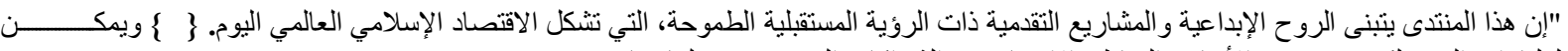

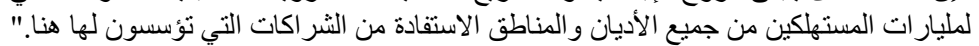

\{From the 9th World Islamic Economic Forum\}

In this example (7), there is an unrecovered implicit DM that was not dealt with properly, due perhaps to a fast examination of the context. In the SLT, there is an implicit DM which can be understood at the beginning of the second sentence. The implicit DM here is so or consequently, which has the function of demarcating a causal relation that is manifested in the SLT between the sentence that comes before the implicit DM, and the one that follows the implicit DM in which the second sentence is the effect that is caused by the first one, i.e., the sentence "Billions of consumers, of every faith and region, can benefit from the partnerships you make here. I wish you every success" is an effect of the first sentence, the cause. This is the underlying coherence of the SLT that should be remain constant in the TL. Being not fully cognizant of such a hidden structural relationship, the Royal Court translators seem to have misunderstood such an implicit DM, the reason why they employed a wrong DM, i.e., the Arabic additive wa in the TLT, that declines to play the causal role of so or consequently, i.e. a cohesion shift, and that eventually declines to salvage the required coherence, i.e., a coherence shift.

In this context, the simple additive DM wa does not convey the sense of the consequent relation that should be figuring between the two sentences in the TLT. As it has been indicated earlier on, the Arabic DM wa is a co-ordinator that can be used as a cohesion-building device that functions exactly the same as the English DM and. Linguistically, the Arabic DM wa-bittaali وبالتشالي (i.e. so/consequently) can be said to be equivalent to the English DM so in terms of meaning and function, and so, it can be a proper translation alternative. From a translational point of view, the Arabic DM wa-bittaali وبالتالي, which is used in Arabic to present a causal relation between sentences can do most of the required job in the TLT, i.e., it can achieve an identical level of cohesion and coherence as that achieved in the SLT, as the following suggested translation can show:

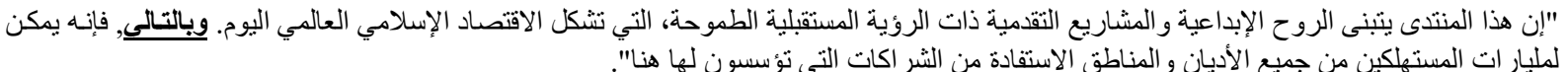

(8a) SL Text:

"I have called on the international community to join Jordan in breaking the impasse and pressing for active negotiations to end this conflict once and for all. \{ \} We must act while there is still a chance."

(8b) TL Text:

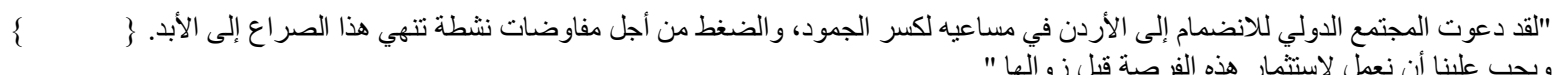

\{From the World Economic Forum Annual Meeting\}

As it can be observed in the above example (8), there is an implicit DM that can be comprehended at the beginning of the second sentence (15a); this is the conjunctive adverbial DM therefore: a type of adverb that joins together two independent clauses. This DM is used in English for deductive reasoning, and it also implies that an avowal is to be stated. Thus, the sentence "We must act while there is still a chance" reflects the kind of deductive reasoning and avowal made after "calling on the international community to join Jordan in breaking the impasse and pressing for active negotiations to end this conflict once and for all". Such a coherence should be invariant in TL; yet, this does not seem to be the case in the provided TLT suggested by the Royal Court translators, as unknowingly, they connected up the two sentences with the additive Arabic DM, which caused not only a cohesion shift, but also a traceable coherence shift as well. An adequate Arabic counterpart DM for it can be lithalika لذلك which can serve the same cohesion function and construct, more or less, the same type of coherence, as the following proposed translation can show:

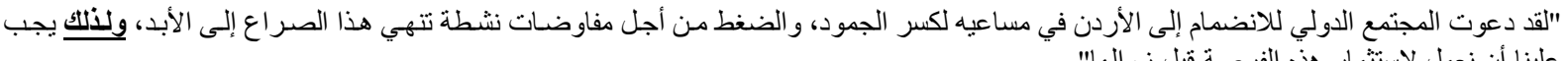

\subsection{No Translation is Given for the Explicit SL DMS}

Under this problem, four illustrative examples will be given. In the TLTs provided by the Royal court translators, curly brackets are used as to point to the place where explicit SL DMs have been omitted in the TLT. 
(9a) SL Text:

"Since then, new and comprehensive constitutional amendments, as well as new laws, have created a matrix of institutions and principles to support our path of reform and democratisation."

(9b) TL Text:

\{ بسن قو انين حديثة أدت بمجملها إلى نشوء منظومـة من المؤسسـات والمبـادئ

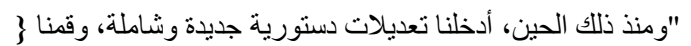
الداعمة لمسار الإصلاح و الديمقر اطية في بلدنا.

\{From Pre-67th Plenary Session of the United Nations General Assembly\}

As far as this example (9) is concerned, the TLT provided above cannot be considered a faithful translation in terms of dealing with the DM as well as. Obviously, this cohesion-building DM was not rendered satisfactorily by the Royal Court translators. Looking at this text-in-context, it can be realized that such a DM is used in the SLT to emphasize that a matrix of institutions and principles are created not only by new and comprehensive constitutional amendments, but on equal footing, by new laws. To achieve a similar cohesion and coherence in the TLT, the DM as well as should not have been ignored translationally. It is crucially important to point out that the additive DM wa used at the beginning of the second clause of the sentence, i.e., the first DM in the following clause

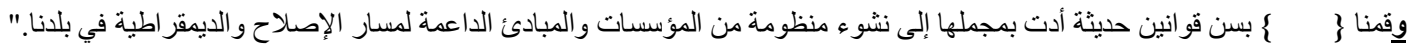

is mandatory in a co-ordinated structure like this; it must be used to connect up the two clauses of this compound sentence, and so, it can never be considered a real translation for the DM as well as.

Actually, this implies that the translators ignored this DM unjustifiably, thereby triggering a cohesion shift, and in tandem, a coherence one. Such a significant DM should have been translated pragmatically into the TL as ithafatan ila thalika إضـافة إلى ذلك with commas before and after the phrase i.e., before the DM as well as and after the noun phrase 'new laws'; commas should be used in order to let the readers grasp the fact that the Arabic word bimujmaliha بمجملها (i.e., as a whole) that figures in the same linear progression refers to two important ingredients that stand on equal footing: 'new and comprehensive constitutional amendments' as well as 'new laws' (not just the 'new and comprehensive constitutional amendments' alone). However, the following can be deemed a compensatory translation in terms of cohesion and coherence:

"ومنذ ذلك الحين، أدخلنا تعديلات دستورية جديدة وشاملة، وقمنا إضافة إلى ذلك بسن قو انين حديثة, أدت بمجملها إلى نشو منظو منظومة من المؤسسات و المبادئ

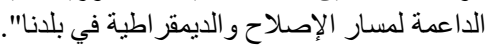

(10a) SL Text:

"We are determined to keep leveraging Jordan's strengths. First and foremost are our people: talented, educated, techsavvy and globally aware."

(10b) TL Text:

\{ وفي مقدمتها شعبنا العزيز، العنصر البشري الموهوب المتعلم والبارع

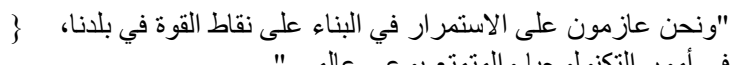

\{From the 9th World Islamic Economic Forum\}

Casting a quick look at this example (10), the TLT shows that the temporal DM first and foremost in (19a) was partially translated into wa-fi muqaddimatiha وفي مقدمتها which only captures the meaning and function of the first word, i.e., first, in this DM. Being so much affected by the first element of this DM, i.e. first, it is conspicuous that the Royal Court translators did not seem to have grasped the pragmatic meaning and function of the DM first and foremost, as they reduced its meaning to something equivalent to on top or on the lead. In fact, this DM is semantically and syntactically inseparable and indivisible: it should be dealt with as if it is one syntactic stretch having one semantic unit. To translate only the first part of the DM affects the overall surface connectivity: the way the first part is related to the second one and vice versa. This cohesion shift is extricably bound up to affect the overall connectivity teething under the surface.

The proper pragmatic meaning of this DM in Arabic is awwalan wa-'aakhiran أولاوآخرا but not awwalan alone. The provided translation wa-fi muqaddimatiha وفي مقدمتها أو لا لا is equivalent, to a large extent, to an option, as it has just been indicated, seems to have affected both the cohesion and coherence of the text. In other words, the SLT and the TLT do not match with respect to the needed level of cohesion and coherence as a result of tampering with the pragmatics of this important DM. The grammatical system of Arabic entails, for using the DM awwalan wa-'aakhiran أولاوآخـرا , recovering the relative pronoun and subject, omitted at the beginning of the second sentence, i.e., wal-lati hiya والتي هي i.e. which is omitted just before the DM first and foremost. The following translation is thought to be a more suitable one that can reflect all that has been just mentioned:

"ونحن عازمون على الاستمر ار في البناء على نقاط القوة في بلدنا، والتى هى أولا وآخرا شعبنا العزيز، العنصر البشري الموهوب المتعلم و البارع في أمور

التكنولوجيا والمنمتع بوعي عالمي". 
(11a) SL Text:

"Jordan seeks a House of the Future that includes all. We are building our future on the solid foundation of majority consensus, minority rights, a democratic culture of active citizenship, and peaceful, evolutionary change.

My Friends,

The Syrian people must $\underline{\text { also }}$ have a future... and for that, the international community must act.”

(11b) TL Text:

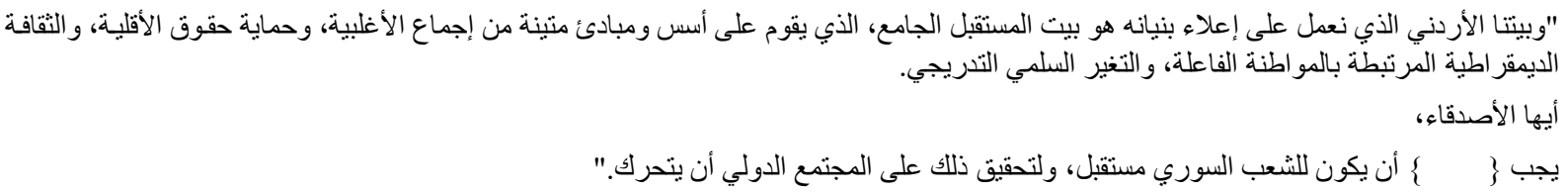

\{From the Plenary Session of the 68th General Assembly of the United Nations\}

In example (11a) above, the English DM also, whose function is to add information, was inconceivably deleted by the Royal Court translators in the TLT. Thus, this DM can be considered an important pointer that can communicate over to the readers the idea that Jordanians are interested in the future of the Syrian people in the same manner they are interested in their own future, i.e., Jordanians have as the same interest in the Syrians' future as the Syrians themselves. However, neither this explicit structural relationship, i.e., this cohesion cementing, nor the implicit structural relationship, i.e., the undergirding coherence, was conveyed in the TLT. In other terms, dropping out this DM from the TLT not only engendered a cohesion shift, but also a tantamount coherence shift. Therefore, the function the DM also serves should be retained in the Arabic version. The Arabic DM kathalika كند (i.e. also) can be considered a good translation counterpart for the English DM also, as it can convey the ostensible sense, i.e., the cohesion relationship as well as the covert coherence relationship holding between the two sentences.

Syntactically speaking, the DM kathalika كذنك can be used to connect up two clauses or sentences explicitly in a manner that the second proposition in the second clause or sentence draws back emphatically on the proposition of the first clause or sentence. This is also being enhanced by the first letter of the DM, i.e., the kaaf كاف (i.e. S lit. like/as), which serves the function of drawing similitude, that is, the second proposition operates in the same manner/in the same way the first one does. Lastly, the Royal Court translators should have cemented up the last sentence with the preceding one by inserting the additive DM wa just before the word yajib يجب, a grammatical necessity in Arabic; yet, another oversight that should be taken care of in any improved translation. In light of all that has been said, the following polished translation can be proposed:

(12a) SL Text:

$$
\text { "وِيجب كنلك أن يكون للشُب السوري مستقبل، ولتحقيق ذلك على المجتمع الدولي أن يتحرك". }
$$

"Earlier this year, in Amman, we succeeded in getting both sides back to the table for exploratory talks. Then positive traction stopped again."

(12b) TL Text:

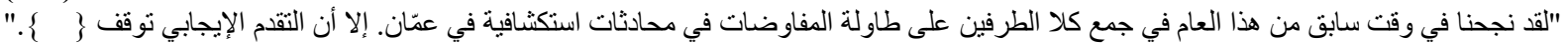
\{From Pre-67th Plenary Session of the United Nations General Assembly\}

As far as example (12) is involved, the DM again signals the fact that this is not the first positive traction to take place; rather, there has been some previous positive traction. It also means that this is not the first time such a positive traction stops, i.e., it implies that it stopped in the past, and this time is not different as it stopped once again. Indeed, this particular coherence running under the SLT's surface cannot be maintained in the TLT without translating the cohesion-building marker, again. Translationally speaking, this DM was left out in (25b): إلا أن التقدم الإيجابي توقف, thereby reflecting a lack of awareness on the part of the Royal Court translators. Omitting this marker creates both a translationally-related cohesion gap that inevitably is wired to create a parallel translationally-related coherence gap in the TLT. Thus, the DM again should be properly rendered into the TL in order to achieve a similar level of cohesion and coherence.

In fact, Arabic has an equivalent DM, with two variants for again: marratan ukhra كـرة أخرى or taratan ukhra تنارة أخرى (i.e., again/once more) that is envisaged to be a better translation choice in this context. The prepositional phrase can also be utilized to convey the pragmatic meaning, and serve the function of the English DM again, e.g., min jadeed من جديد, as it can be shown in the following three proposed translations that capture the three translation options:

$$
\begin{aligned}
& \text { "لقد نجنا في وقت سابق من هذا العام في جمع كلا الطرفين على طاولة المفاوضـات في محادثات استكثـافية في عمّان. إلا أن التقدم الإيجابي نوقف مرة } \\
& \text { أخرى". } \\
& \text { "لقد نجحنا في وقت سابق من هذا العام في جمع كلا الطرفين على طاولة المفاوضـات في محادثات استكثـافية في عمّان. إلا أن التقدم الإيجـابي توقف تـارة } \\
& \text { أخرى". } \\
& \text { "لقد نجنا في وقت سابق من هذا العام في جمع كلا الطرفين على طلاولـة المفاوضـات في محادثات استكثـافية في عمّان. إلا أن التقدم الإيجابي توقف من }
\end{aligned}
$$




\section{Conclusion}

The central concern of this study has been with how DMs play a main role in achieving a remarkable degree of explicit connectedness, i.e., in achieving cohesion within translated texts, and how tampering with the SLT's cohesion grid can impinge upon the undergirding implicit connectedness, i.e., the coherence grid. In other words, the study has revealed that any given cohesion shift in the act of translating would necessarily lead to a parallel coherence shift. This conclusion is supported by Bell, 1991; Hatim and Mason, 1990; Hatim and Munday, 2004; Kostopoulou, 2007. As a consequence, a considerable translation loss is usually incurred. However, this translation loss cannot be palliated without a proper translation of both the explicit as well as the implicit DMs. In light of the qualitative analysis of data, three main problems have been isolated: (a) mistranslating explicit SL DMs, (b) no translation is given for the implicit SL DMs, and (c) no translation is given for the explicit $S L D M s$. Now let us take up each of them individually.

The study has shown that explicit SL DMs have been mistranslated from English into Arabic in various contexts. Such mistranslations seem to have arisen from not only a misunderstanding of the SL context and meaning, role, and/or function of the explicit DM in question, but also from a similar misunderstanding of the meaning, role, and/or function of the TL DMs, i.e. Arabic DMs. This conclusion is echoed by Baker (1992) and Edmondson (1981, quoted in Blum-Kulka, 2000, p. 304), who equates cohesion and coherence with the text's interpretability. It has also been found that implicit SL DMs were overlooked in translation, i.e., no translation has been given to the (existing) implicit DMs, detected and analyzed in the selected examples. This conclusion can be accounted for by the fact that these implicit DMs are normally much more difficult to spot and translate than the explicit ones, a fact which complicates the job of the translator. This conclusion substantiates Dressler (1998) and de Beaugrande's (1980, p. 19) continual interaction of TEXT-PRESENTED KNOWLEDGE with PRIOR KNOWLEDGE OF THE WORLD". In other terms, implicit DMs are likely to skip the recognition of translators, and so, Royal Court translators seem to have declined to develop a sensitivity towards hidden or implicit DMs in the discussed examples. This explains why the Royal Court translators mimicked the English writing style in the implicitation aspect in particular. Since Arabic cannot tolerate implicitation like English, a workable solution that has been suggested to this problem is to explicate the implicit.

As far as the third problem is concerned, the study shows that no translation has been given to explicit SL DMs. These explicit DMs were used in the SL as to build cohesion and coherence relations, but have been left out in the TLTs, thereby causing a considerable translation loss that should be compensated for in one way or another. Indeed, the study has found that in certain cases, the deletion strategy was employed by the Royal Court translators in dealing with the explicit DMs, as the discussion has already shown. So, lack of awareness and lack of a careful examination of the SL context on the part of the translators were selfevident not only in dealing with implicit DMs, but also in dealing with explicit DMs. This conclusion draws on Blum-Kulka's text-focused shifts that are engendered by "particular choices made by a specific translator, choices that indicate a lack of awareness on the translator's part of the SL text's meaning potential" (BlumKulka, 2000, p. 309; see also Blum-Kulka, 1986, p. 19). Finally, the study has shown that the Arabic additive wa (i.e. g, lit. and) has been extensively used by the Royal Court translators as a "magic DM" for forging most of the required cohesion-related structural relationships.

\section{References}

Baker, M. (1992). In other words: A coursebook on translation. London/New York: Routledge.

Beaugrande, R.de \& Dressler, W. U. (1981). Introduction to text linguistics. London/New York: Longman.

Bell, R. (1991). Translation and translating: Theory and practice. London:Longman.

Blakemore, D. (2002). Relevance and linguistic meaning: The semantics and pragmatics of discourse markers. Cambridg: Cambridge University Press.

Blum-Kulka, S. (1986). Shifts of cohesion and coherence in translation. In J. House and S. Blum-Kulka (Eds.), Interlingual and intercultural communication: Discourse and cognition in translation and second language acquisition studies (pp.17-35). Tübingen: Narr.

Blum-Kulka, S. (2000). Shifts of cohesion and coherence in translation. In L. Venuti (Ed.) The translation studies reader (pp. 298-313). London \& New York: Routledge.

Carrell, P. (1982). Cohesion is not coherence. TESOL Quarterly, 16(4), 476-488.

Chilton, P. (2004). Analysing political discourse: Theory and practice. London: Routledge.

Dickins J. et al. (2002). Thinking Arabic translation. A course in translation method: Arabic to English. London \& New York: Routledge.

Hatim, B. \& Mason, I. (1990). Discourse and the translator. Language in Social Life Series. London/New York: Longman.

Hatim, B. and Munday, J. (2004). Translation: An advanced resource book. Abingdon: Routledge. 
Hu, H. C. (1999). Cohesion and coherence in translation theory and pedagogy. Word, 50 (1), 33-46.

Halliday, M. (1994). Introduction to functional grammar. London: Edward Arnold.

Halliday, M. and Hasan, R. (1976). Cohesion in English. London: Longman.

(1995). Cohesion in English. English Language Series.London/New York: Longman.

Kostopoulou, G. (2007). The role of coherence in text approaching and comprehension: Applications in translation didactics". Meta, 52 (1), 146-155.

Neubert, A. and Shreve, G. (1992). Translation as text. Kent, Ohio, and London: The Kent University Press.

Papegaaij, B. and Schubert, K. (1988). Text coherence in translation. Dordrecht: Foris.

Rey, J. (1997). Discourse markers a challenge for natural language processing. AlCommunications, 10(3- 4), $177-184$.

Rouchota, V. (1996). Discourse connectives: What do they link? UCL Working Papers in Linguistics, 8 (199- 214), pp. $1-15$.

Sanders, R. E. (1987). Cognitive foundations of calculated speech. Albany: StateUniversity of New York Press.

Schiffrin, D. (1987). Discourse markers. Cambridge: Cambridge University Press.

Stubbs, M. (1983). Discourse analysis: The sociolinguistic analysis of natural language. Chicago: University of Chicago Press.

Sun, W. (2013). The importance of discourse markers in English learning and teaching. Theory and Practice in Language Studies, 3(11), 2136- 2140.

Tafish, R. and Tahaineh, Y. (2011). Pitfalls encountered by bilingual Arab learners in translating the Arabic discourse marker 'Oumma' into English. Theory and Practice in Language Studies, 1 (3), 226-238.

Thompson, G. (1996). Introducing functional grammar. London: Edward Arnold.

Van Dijk, T. (1995). On macrostructures, mental models, and other inventions: A brief personal history of the KintschVan Dijk theory." In C. Weaver, S. Mannes and C. Fletcher (Eds.), Discourse comprehension: Essays in honor of Walter Kintsch (pp. 383-410). Hillsdale, NJ: Lawrence Erlbaum.

Vehmas-Lehto, I. (1991). Cohesion flaws in translations. In S. Tirkonen-Condit (Ed.), Empirical research in translation and intercultural studies (pp. 171-181). Tübingen: Gunter Narr.

Ventola, E. (1997). "Thematic development and translation. In M. Ghadessy (Ed.), Thematic development in English texts (pp. 85-104). London and New York: Pinter.

Walrod, M. (2006). The marker is the message: The influence of discourse markers and particles on textual meaning. Paper presented at the tenth international conference on Austronesian linguistics. 17- 20 January 2006. Puerto Princesa City, Palawan, Philippines. Retrieved from: http://www.sil.org/asia/phlippines/ical/papers.html.

Weissberg, R. C. (1984). Given and new: Paragraph development models from scientific English. TESOL Quarterly, 18(3), 485-500.

Yehia, T. (2015). Use of discourse markers: A case study of English writing by Yemeni students. Language in India, 15 (6), 217- 235.

Varela Pérez, J.R. (1999). Theme, cohesion devices and translation. Estudios Ingleses de la Universidad Complutense, 7, 163-176. 